\title{
Association between Blood Glucose and cardiac Rhythms during pre-hospital care of Trauma Patients - a retrospective Analysis
}

Janett Kreutziger ${ }^{1 *}$, Stefan Schmid ${ }^{2}$, Nikolaus Umlauf ${ }^{3}$, Hanno Ulmer ${ }^{4}$, Maarten W. Nijsten ${ }^{5}$, Daniel Werner ${ }^{6}$, Thomas Schlechtriemen ${ }^{7,8}$ and Wolfgang Lederer ${ }^{9}$

\begin{abstract}
Background: Deranged glucose metabolism is frequently observed in trauma patients after moderate to severe traumatic injury, but little data is available about pre-hospital blood glucose and its association with various cardiac rhythms and cardiac arrest following trauma.

Methods: We retrospectively investigated adult trauma patients treated by a nationwide helicopter emergency medical service (34 bases) between 2005 and 2013. All patients with recorded initial cardiac rhythms and blood glucose levels were enrolled. Blood glucose concentrations were categorised; descriptive and regression analyses were performed.

Results: In total, 18,879 patients were included, of whom 185 (1.0\%) patients died on scene. Patients with tachycardia $(\geq 100 / \mathrm{min}, 7.0 \pm 2.4 \mathrm{mmol} / \mathrm{L} p<0.0001)$, pulseless ventricular tachycardia $(9.8 \pm 1.8, \mathrm{mmol} / \mathrm{L}, p=0.008)$ and those with ventricular fibrillation $(9.0 \pm 3.2 \mathrm{mmol} / \mathrm{L}, \mathrm{p}<0.0001)$ had significantly higher blood glucose concentrations than did patients with normal sinus rhythm between 61 and 99/min $(6.7 \pm 2.1 \mathrm{mmol} / \mathrm{L})$. In patients with low $(\leq 2.8 \mathrm{mmol} / \mathrm{L}$, $7 / 79 ; 8.9 \%, \mathrm{p}<0.0001)$ and high (>10.0 mmol/L, 70/1271; 5.5\%, $\mathrm{p}<0.0001)$ blood glucose concentrations cardiac arrest was more common than in normoglycaemic patients (166/9433, 1.8\%). ROSC was more frequently achieved in hyperglycaemic (> $10 \mathrm{mmol} / \mathrm{L} ; 47 / 69 ; 68.1 \%)$ than in hypoglycaemic $(\leq 4.2 \mathrm{mmol} / \mathrm{L} ; 13 / 31 ; 41.9 \%)$ trauma patients $(p=0.01)$.

Conclusions: In adult trauma patients, pre-hospital higher blood glucose levels were related to tachycardic and shockable rhythms. Cardiac arrest was more frequently observed in hypoglycaemic and hyperglycaemic pre-hospital trauma patients. The rate of ROSC rose significantly with rising blood glucose concentration. Blood glucose measurements in addition to common vital parameters (GCS, heart rate, blood pressure, breathing frequency) may help identify patients at risk for cardiopulmonary arrest and dysrhythmias.
\end{abstract}

Keywords: Trauma, Cardiac arrest, Tachyarrhythmia, Bradyarrhythmia, Pre-hospital care, Blood glucose

\section{Background}

In-hospital hypo- and hyperglycaemia are known to be predictive for outcome in several acute and critical diseases [1-3], but especially trauma patients seem to be more prone to poor outcome than are other critically ill patients due to both hyperglycaemia and hypoglycaemia

* Correspondence: janett.kreutziger@i-med.ac.at

${ }^{1}$ Department of Anaesthesia and Intensive Care Medicine, Medical University of Innsbruck, Anichstrasse 35, 6020 Innsbruck, Austria

Full list of author information is available at the end of the article
[4-6]. Survival of trauma patients with out-of-hospital cardiac arrest is still low [7].

There is little data about the association between pre-hospital blood glucose concentration and dysrhythmias or cardiac arrest in trauma patients. The aim of this trial was to analyse the association between pre-hospital blood glucose concentrations and documented cardiac rhythms in trauma patients following arrival of the emergency physician. We particularly focused on the association between cardiac arrest and return of spontaneous circulation (ROSC) among pre-defined blood glucose

(c) The Author(s). 2018 Open Access This article is distributed under the terms of the Creative Commons Attribution 4.0 International License (http://creativecommons.org/licenses/by/4.0/), which permits unrestricted use, distribution, and reproduction in any medium, provided you give appropriate credit to the original author(s) and the source, provide a link to the Creative Commons license, and indicate if changes were made. The Creative Commons Public Domain Dedication waiver (http://creativecommons.org/publicdomain/zero/1.0/) applies to the data made available in this article, unless otherwise stated. 
levels. This information, in addition to vital parameters, could be helpful since measurement of blood glucose is simple, rapid, and inexpensive and may complement clinical assessment of patients at increased risk at the accident site.

The primary outcome of this study was the level of blood glucose observed during various cardiac rhythms in adult trauma patients. Secondary outcome parameter was blood glucose and its association with the rate of cardiac arrest and ROSC on scene. In addition, we also evaluated the predictive value of blood glucose in trauma patients who suffered cardiac arrest during emergency treatment.

\section{Methods}

\section{Study design, inclusion and exclusion criteria}

A retrospective analysis of data from pre-hospital missions conducted by the Helicopter Emergency Medicine Service (HEMS) of Allgemeiner Deutscher Automobil Club (ADAC) in Germany was performed. A nationwide, multicentre study including all 34 ADAC helicopter bases was conducted and all trauma patients treated by ADAC-HEMS between 1 January 2005 and 31 December 2013 were screened for inclusion. Inclusion criteria were adult trauma patients ( $\geq 18$ years) treated by HEMS, in whom initial cardiac rhythms and blood glucose concentrations were documented. Exclusion criteria were interhospital transfers and incomplete or incongruent data recording (demographic data, cardiac rhythm, vital signs, injury pattern, trauma causes and courses). The study was approved by the Ethics Committee of the Medical Association of the Saarland and by the Institutional Review Board.

\section{Data processing}

The following parameters were routinely recorded according to the predefined emergency physician dataset (Minimaler Notarzt-Datensatz, MIND2 [8]) within the observational database of the ADAC $\left(\right.$ LIKS $^{\circ}$ (Luftrettungs-, Informations- und Kommunikations-System)): demographic data, first vital parameters (heart rate, breathing frequency, systolic blood pressure) upon arrival of the professional rescuers, Glasgow Coma Scale (GCS) [9]), trauma mechanism, clinical evaluation of injury severity of the following body regions: head/brain, neck, face, chest, abdomen, thoracic and lumbar spine, pelvis, upper and lower extremities $(1=$ no injury, $2=$ minor injury, $3=$ moderate injury, $4=$ severe injury, not life-threatening, $5=$ severe injury, life-threatening, $6=$ critical injury, life-threatening, $7=$ deadly injury), whole injury pattern $(1=$ single injury, $2=$ multiple injuries, $3=$ polytrauma defined as life-threatening multiple trauma), the modified National Advisory Committee for Aeronautics (NACA) Index [10], $0=$ no injury, $1=$ minor injury, no intervention by a physician necessary; $2=$ minor to moderate injury, ambulatory evaluation, $3=$ moderate to severe injury, not life-threatening, in-patient care necessary, $4=$ severe injury, potentially life-threatening, emergency physician care necessary, $5=$ acute life-threatening injury, $6=$ apnoea and circulatory arrest/resuscitation, $7=$ deceased; of note: we included only patients who were alive on arrival of the HEMS emergency physician at the accident scene). In addition, the given volume, type of drugs administered, and rescue intervals were recorded.

\section{Blood glucose measurement}

Blood glucose (in $\mathrm{mmol} / \mathrm{L}$ ) was measured at the scene with varying point-of-care devices that differed in accuracy and manageability. In most cases, glucose was measured from blood drawn immediately after venous access before any drug or volume administration. Blood glucose concentrations were categorised in groups: $\leq 2.80 \mathrm{mmol} / \mathrm{L}$ (50 mg/dL), 2.81-4.20 $\mathrm{mmol} / \mathrm{L}$ (51$75 \mathrm{mg} / \mathrm{dL}), 4.21-5.55 \mathrm{mmol} / \mathrm{L}(76-100 \mathrm{mg} / \mathrm{dl}), 5.56-$ 7.50 (101-135 mg/dL), 7.51-10.0 mmol/L (135-180 mg/ dL), $10.01-15.0 \mathrm{mmol} / \mathrm{L} \quad(181-270 \mathrm{mg} / \mathrm{dL})$ and $>$ $15.0 \mathrm{mmol} / \mathrm{L}$ (> $270 \mathrm{mg} / \mathrm{dL}$ ). Hypoglycaemia and hyperglycaemia limits are not consistently defined to date and differ strongly in the literature. The thresholds of 2.80 $(50 \mathrm{mg} / \mathrm{dL}), 4.2 \mathrm{mmol} / \mathrm{L}(75 \mathrm{mg} / \mathrm{dL})$ and $5.55 \mathrm{mmol} / \mathrm{L}$ $(100 \mathrm{mg} / \mathrm{dL})$ are commonly used to define various stages of hypoglycaemia; whereas the threshold of $10 \mathrm{mmol} / \mathrm{L}$ (180 $\mathrm{mg} / \mathrm{dL}$, hyperglycaemia) is commonly used to define hyperglycaemia in pre-hospital emergency medicine and in-hospital intensive care medicine. The values between $5.56 \mathrm{mmol} / \mathrm{L}(>100 \mathrm{mg} / \mathrm{dL})$ and $7.50 \mathrm{mmol} / \mathrm{L}$ $(135 \mathrm{mg} / \mathrm{dL})$ are regarded as physiological blood glucose concentrations following normal nutritional intake; values exceeding $15 \mathrm{mmol} / \mathrm{L}(270 \mathrm{mg} / \mathrm{dL})$ are defined as excessive hyperglycaemia $[4,5,11-13]$.

\section{Cardiac rhythm analysis}

Although automatic interpretation of some ECG findings is offered by most ECG devices, the binding diagnosis was performed by the emergency physician on service following immediate monitoring on site. Emergency physicians were trained during their practical year, of which four months were in internal medicine and another four months in anaesthesiology, during five years of specialisation (most of them in anaesthesiology and intensive care medicine), during their post-graduate training in emergency medicine (subspecialty qualification emergency medicine) including minimum 100 missions with ground EMS before applying for further training with HEMS. [14]. Routinely, a 3-lead ECG was established for initial rhythm diagnosis. In patients with signs of ischaemia an additional 12-lead ECG was written. 
Bradyarrhythmia in adults was defined according to current guidelines as a heart rate $\leq 60$ beats per minute [15]. Regular supraventricular bradycardia matches sinus bradycardia. Irregular supraventricular bradycardia included atrial fibrillation with slow ventricular response and sinus rhythms with relevant ventricular or supraventricular extrasystole. Ventricular bradycardia included ventricular escape rhythm, sinus arrest, sino-atrial exit block, high-grade second- and third-degree atrioventricular block, broad complex escape rhythm, and idioventricular rhythm.

Tachyarrhythmia in adults was defined as a heart rate $>100$ beats per minute [15]. Regular tachycardia included sinus tachycardia, atrial tachycardia, paroxysmal supraventricular tachycardia, narrow-complex tachycardia, atrioventricular nodal re-entry tachycardia, sinus node re-entry, junctional tachycardia, Wolff-Parkinson-White syndrome. Irregular supraventricular tachycardia included focal atrial tachycardia, atrial fibrillation with rapid ventricular response as well as sinus tachycardia with relevant supraventricular and ventricular extrasystole. Ventricular tachycardia defined perfusing ventricular tachycardia.

Normofrequent arrhythmia included sinus rhythm with ventricular and supraventricular extra beats and irregular supraventricular arrhythmia with normofrequent ventricular response.

Cardiac rhythms associated with cardiac arrest were asystole, pulseless electrical activity (non-shockable rhythms), and ventricular fibrillation and pulseless ventricular tachycardia (shockable rhythms) [15]. Cardiac arrest was diagnosed according to ECG rhythm analysis (asystole, pulseless electrical activity (PEA), ventricular fibrillation or pulseless ventricular tachycardia), NACA score of 6 or 7, and documented as cardiopulmonary resuscitation. ROSC was measured when spontaneous circulation occurred during cardiopulmonary resuscitation on site. Successful cardiopulmonary resuscitation was defined by both a documented ROSC and a NACA score of 6 on admission.

\section{Statistical analysis}

Statistical analysis was conducted with IBM SPSS Statistics (Release 24.0, 2016, Armonk, NY, USA). The Shapiro-Wilk test was used to test for normal distribution. Following descriptive analysis, the Mann-Whitney $U$ test was used to compare group differences and the chi-square test was performed to detect frequency differences. For the prediction of cardiac arrest (NACA score 6 or 7) we applied a generalised additive model [16] using common vital parameters for model 1 (heart rate, respiratory frequency, systolic blood pressure, GCS) and for model 2 common vital parameters and blood glucose on site. More precisely, the effects of the predictor variables were modelled using penalised regression splines [17] to be able to identify potentially nonlinear relationships between cardiac arrest states with changing vital parameters. The models were estimated using the statistical environment $R$ [18] and the recommended mgcv package [19]. Integrated discrimination improvement (IDI) and net reclassification improvement (NRI) were used to assess the improvement of outcome prediction comparing model 1 and model 2 (STATA/MP, release 13, College Station, TX, USA). Confidence intervals (CI) in this study were $99 \%$. A $p$ value of 0.01 was deemed to be statistically significant.

\section{Results}

\section{Patient population}

Of 51,936 trauma patients, 28,152 patients with recorded ECG findings and glucose concentrations were eligible; 18,879 trauma patients fulfilled the inclusion criteria and were enrolled (13,185 (69.8\%) were male; mean age $50 \pm$ 20 years). In $58.5 \%(11,039 / 18,879)$ of the trauma patients ECG findings were within normal limits, in $31.6 \%$ (5958/18,879) ECG showed tachycardia and 5.7\% (1072/ $18,879)$ had bradycardia. Cardiac arrest was diagnosed in $466(2.5 \%)$ of the trauma patients; 185 patients $(1.0 \%)$ died on the scene (Fig. 1, Table 1), and 3064 (16.3\%) patients had single injuries (predominantly severe to life-threatening head injuries), while 13,031 (69.0.1\%) patients had multiple injuries, and 2784 (14.7\%) patients were polytraumatised.

\section{Blood glucose and cardiac rhythms}

Patients with tachycardia ( $\geq 100 / \mathrm{min}, 7.0 \pm 2.4 \mathrm{mmol} / \mathrm{L}, p<$ $0.0001)$, pulseless ventricular tachycardia $(9.8 \pm 1.8, \mathrm{mmol} /$ $\mathrm{L}, p=0.008)$ and patients with ventricular fibrillation $(9.0 \pm$ $3.2 \mathrm{mmol} / \mathrm{L}, \mathrm{p}<0.0001)$ had higher blood glucose than did patients with normal sinus rhythm of $61-99 / \mathrm{min}(6.7 \pm$ $2.1 \mathrm{mmol} / \mathrm{L})$. Patients with asystole $(6.7 \pm 2.4 \mathrm{mmol} / \mathrm{L})$ or pulseless electrical activity (PEA, $6.6 \pm 2.3 \mathrm{mmol} / \mathrm{L}$ ) and bradycardia $(6.9 \pm 2.4 \mathrm{mmol} / \mathrm{L})$ had comparable blood glucose levels. (Table 1).

\section{Blood glucose and cardiac arrest}

The frequency of patients with cardiac arrest was highest in patients with either hypoglycaemia $(\leq 4.2 \mathrm{mmol} / \mathrm{L} ; 31 /$ $641 ; 4.8 \%, \leq 2.8 \mathrm{mmol} / \mathrm{L} ; 7 / 79 ; 8.9 \%$ ) or hyperglycaemia (>10 $\mathrm{mmol} / \mathrm{L} ; 68 / 1270 ; 5.6 \%$, > $15 \mathrm{mmol} / \mathrm{L} ; 16 / 264$; 6.1\%) and lowest in patients with blood glucose of > $4.2-7.5 \mathrm{mmol} / \mathrm{L}$ (262/13,780; 1.9\%). (Fig. 3) In 80\% (174/ 218) of the patients with asystole or pulseless electrical activity a life-threatening polytrauma was diagnosed, whereas $20(60.6 \%)$ of the 33 patients with ventricular fibrillation or ventricular tachycardia suffered from a single injury. 


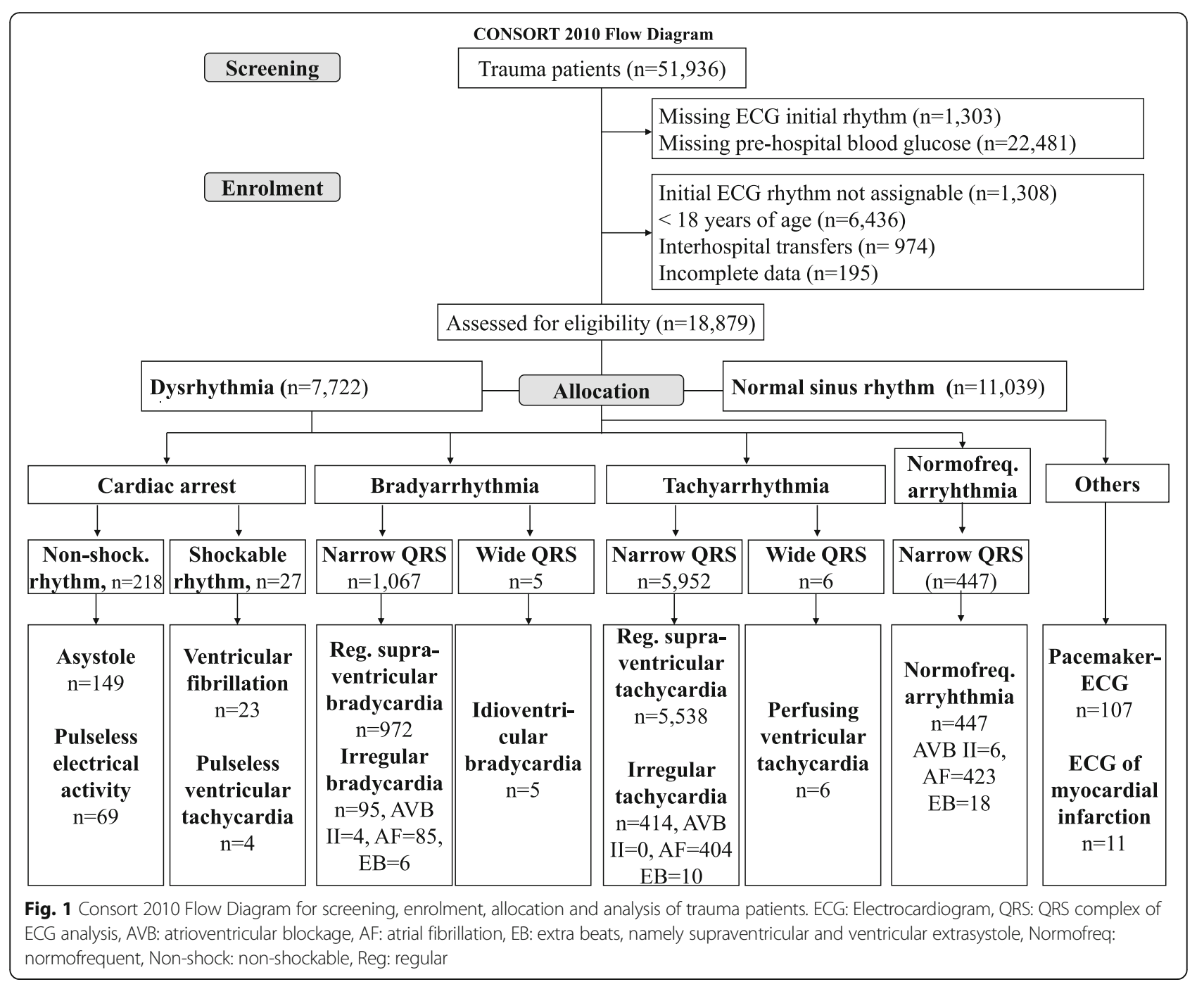

Especially in polytraumatised patients, pre-hospital blood glucose showed a significantly U-shaped association with the rate of patients with cardiac arrest $(p<$ 0.0001 ), with the lowest rate of cardiac arrest being in patients with blood glucose at $5.56-7.5 \mathrm{mmol} / \mathrm{L}(112 /$ $1340,8.4 \%)$ and the highest rate in hypoglycaemic patients $(\leq 4.2 \mathrm{mmol} / \mathrm{L}, 26 / 82,31.7 \%)$. This U-shaped pattern was less marked in patients with a single injury and was not observed in patients with multiple injuries. (Fig. 2) This U shape was also found in all age categories $(\mathrm{p}<0.0001)$. In patients $\leq 40$ years the rate of cardiac arrest was higher with hyperglycaemia $(>10 \mathrm{mmol} / \mathrm{L}, 14 /$ $178,7.9 \%$; > $15 \mathrm{mmol} / \mathrm{L}, 4 / 40,10.0 \%)$, whereas in patients $>40$ years the rate of cardiac arrest was higher with blood glucose levels $<4.2 \mathrm{mmol} / \mathrm{L}(22 / 363,6.1 \%)$.

Prevalence of dysrhythmias and cardiac arrest was related to age. Analysing age and blood glucose for their combined association to cardiac arrest revealed that young age $<40$ years and high blood glucose as well as age $>$ 65 years and low blood glucose indicate an increased risk for cardiac arrest in all trauma patients. (Fig. 3) No significant differences were seen between mean peripheral oxygen saturation in bradycardia, tachycardia or in normofrequent rhythms.

In patients with minimal circulation (heart rate $>30$ / min and systolic blood pressure $>40 \mathrm{mmHg} ; n=18,633$ ) [20] on arrival of the emergency physician, pre-hospital blood glucose non-significantly improved the prediction of cardiac arrest (surrogate parameters NACA score 6 or 7 , area under the curve 0.881 with common vital signs, 0.886 for common vital signs and blood glucose; IDI $p=$ 0.03 , NRI $p=0.68$ in all patients) in comparison to prediction by common vital signs alone (heart rate, breathing frequency, Glasgow Coma Scale, blood pressure).

\section{Blood glucose and ROSC}

Blood glucose was measured in 466 patients with pre-hospital traumatic cardiac arrests.

The frequency of ROSC (NACA score 6) in all patients with cardiac arrest (NACA score 6 or 7) increased with 
Kreutziger et al. Scandinavian Journal of Trauma, Resuscitation and Emergency Medicine (2018) 26:58

Page 5 of 10

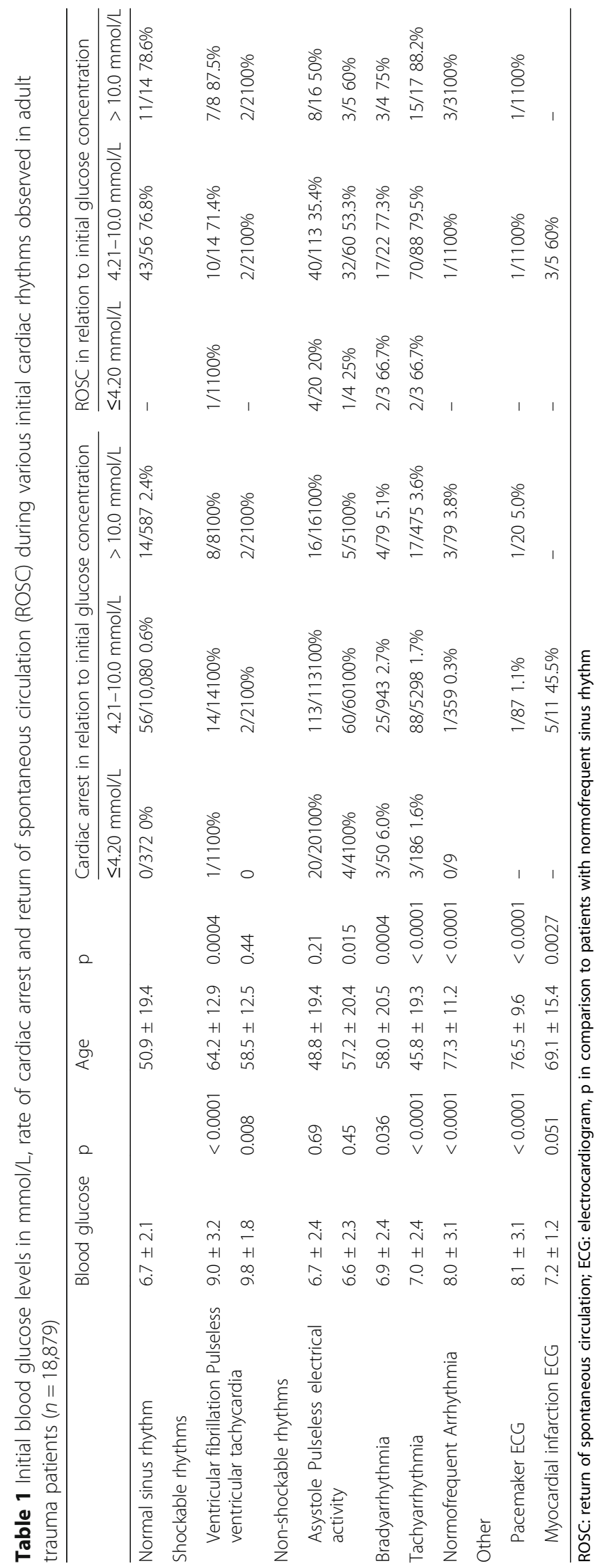




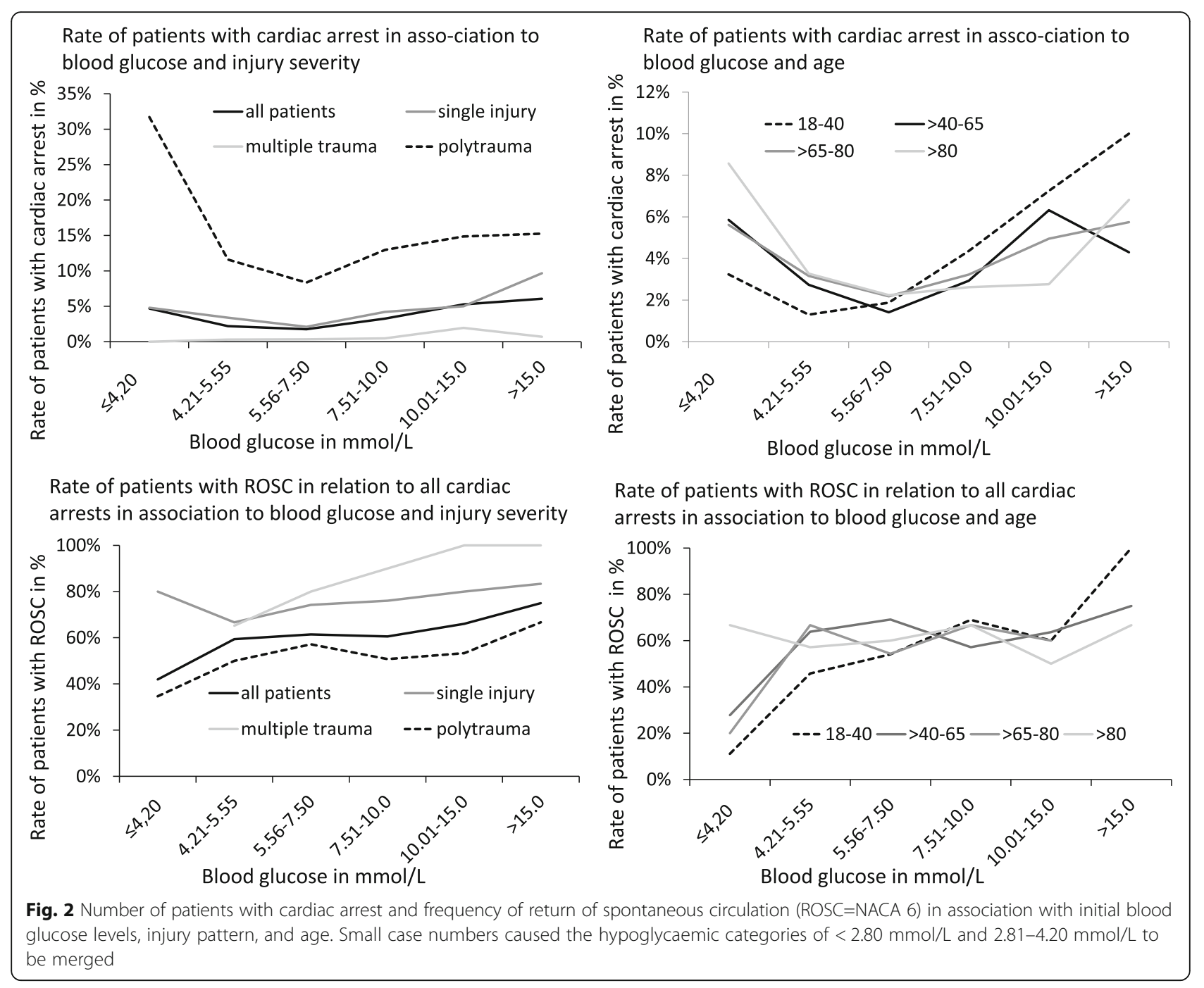

rising blood glucose: from 13/31 (41.9\%) in patients with blood glucose $\leq 4.2 \mathrm{mmol} / \mathrm{L}$, to $221 / 366(60.4 \%)$ in patients with blood glucose of $4.21-10.0 \mathrm{mmol} / \mathrm{L}$, to $47 / 69$ (68.1\%) in patients with blood glucose of $>10 \mathrm{mmol} / \mathrm{L}$. The rate reached even $100 \%$ in younger patients $(18-$ 40 years) with excessive hyperglycaemia (> $15 \mathrm{mmol} / \mathrm{L})$. (Fig. 3).

Only 43 (54\%) of 79 patients with hypoglycaemia $\leq 2.8 \mathrm{mmol} / \mathrm{L}$ and $166(26 \%)$ of 641 patients with hypoglycaemia $\leq 4.2 \mathrm{mmol} / \mathrm{L}$ received iv glucose therapy. In hypoglycaemic patients with cardiac arrest and documented iv glucose administration, there was a trend towards higher survival rate in comparison to hypoglycaemic patients without documented glucose administration: hypoglycaemia $\leq 4.20 \mathrm{mmol} / \mathrm{L}$ : cardiac arrest $31 \mathrm{pa}-$ tients, of whom six received iv glucose, four of them survived to hospital admission (ROSC) $=66.7 \%, 25$ received no iv glucose, eight of them survived to hospital admission $($ ROSC) $=32 \%, p=0.174$.

\section{Discussion}

In this retrospective analysis of 18,879 trauma patients we demonstrate that prehospital dysrhythmia was associated with significantly deranged blood glucose concentrations. Patients with cardiac arrest presented with blood glucose concentrations in a U-shaped manner. This was especially evident in polytraumatised patients $\leq 40$ years with either hypoglycaemia (32\%) or hyperglycaemia (15\%). Furthermore, the rate of ROSC correlated positively with initial blood glucose levels.

In cardiac arrest patients with high-frequency rhythms such as tachycardia or ventricular fibrillation we observed significantly higher blood glucose levels than in patients with pulseless electrical activity and asystole. To put it another way, $77.4 \%$ of cardiac arrest patients with hypoglycaemia $(\leq 4.2 \mathrm{mmol} / \mathrm{L})$ presented with asystole or pulseless electrical activity, whereas only one patient presented with ventricular fibrillation. The heart relies primarily on augmented glucose utilisation to meet 


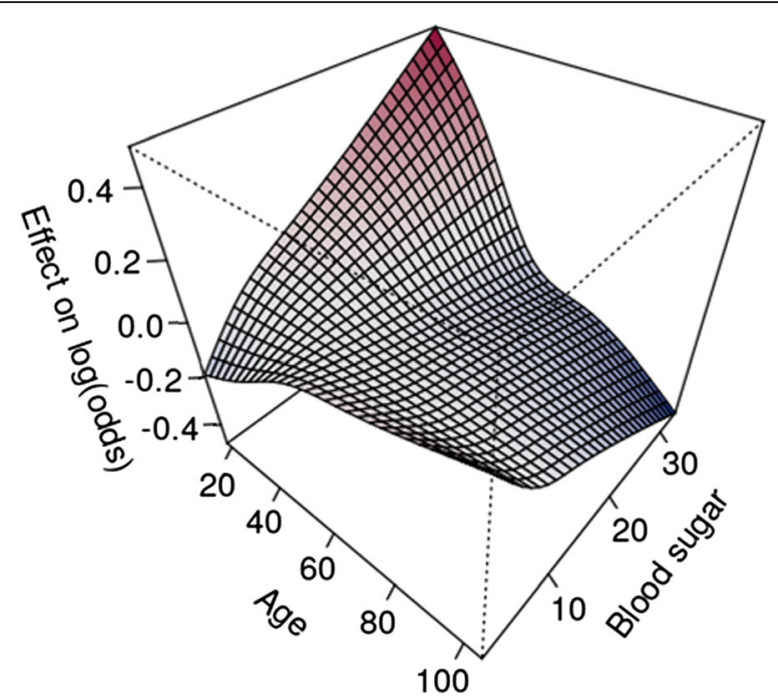

Fig. 3 Estimated smooth interaction effect of age and blood glucose of the GAM model 2 (vital signs and blood glucose). The figure indicates an increased risk for NACA 6 or 7 to result in higher blood glucose values for young people and the inverse effect for people older than 40 years

energetic needs for force generation. Increased heart work, usually elicited by catecholamines, increases carbohydrate oxidation because of activation of the pyruvate dehydrogenase complex [21]. Amazingly, administration of i.v. glucose was recorded in only half of the patients with severe hypoglycaemia and in only one-quarter of the patients with moderate hypoglycaemia.

Except in patients with diabetes mellitus, acute hyperglycaemia following trauma is mainly a consequence of distress causing a hypothalamic-hypophysic-adrenal stress response modulated by trauma severity, incidence of shock, and age [22-24]. Haemorrhagic shock and hypoxaemia belong to the strongest stressors in mammals, triggering highest levels of cortisol and catecholamines [24-26]. They lead to release of pro-inflammatory cytokines in the liver [27, 28], trigger glycogenolysis, and gluconeogenesis by degradation of muscle lactate, glucoplastic amino acids, and glycerol in liver and kidneys, and lipolysis [29-31]. Simultaneously, tumor necrosis factor $\alpha$ induces a peripheral insulin resistance [32]. This stress response-induced hyperglycaemia supports initial steps of immune defense and wound healing. In addition, hyperglycaemia leads to a higher concentration gradient to tissues with disturbed microcirculation and increased need, especially in the brain following injury [33-35], which eases glucose uptake. Over and above this, hyperglycaemia may improve cardiac function and resistance during stress and osmotic effects counteract blood loss [36-39].

In severely injured patients who were found to be hyperglycaemic on arrival of the emergency physician, circulation presumably lasted long enough to develop a stress response. In contrast, patients with asystole or pulseless electrical activity had less time for a physical stress response. This assumption is supported by the fact that $80 \%$ of the patients with asystole or pulseless electrical activity were polytraumatised, whereas patients with ventricular fibrillation or ventricular tachycardia had suffered a single injury in $60 \%$ of the cases in our study.

The potentially positive effects of hyperglycaemia in the acute post-traumatic situation are accompanied by negative sequelae from prolonged hyperglycaemia known as "diabetes of injury" [40,41], which seems to be more pronounced than diabetes mellitus-induced hyperglycaemia. [42, 43].

The high frequency of hypoglycaemic patients in cardiac arrest needs further investigation. The prevalence of diabetes mellitus among adults in the German population averages about 7-8\%, with increasing prevalence depending on age [44]. Theoretically, in some of the diabetic trauma patients hypoglycaemia may have been a consequence of anti-hyperglycaemic drug overdose from insulin or anti-diabetic drugs. In addition, hypoglycaemia in non-diabetic patients could have resulted from extensive shivering due to hypothermia, due to exposure to cold and wet environment, but also from chronic liver disease, intoxication, or severe liver and kidney trauma [22, 23, 45-48].

The finding that the rate of successful resuscitation attempts correlated with blood glucose levels, especially in polytraumatised and young patients, raises the question whether blood glucose levels need to be increased during CPR in patients with traumatic cardiac arrest. Some studies support the hypothesis that hyperglycaemia could be beneficial during cardiac arrest: Nehme et al. observed that diabetes affects at least one in five patients who have had an out-of-hospital cardiac arrest and is associated with poorer survival and 12-month functional recovery. In contrast, a mild-to-moderate elevation of pre-hospital blood glucose level was associated with improved survival and functional recovery, which were independent of diabetes status [49]. Mentzelopoulos found better outcome by administering - among others - blood glucose-increasing steroids for resuscitation of in-hospital cardiac arrest [50]. In animal studies, hyperglycaemia during cardiac arrest led to greater cerebral oxygenation [51], and blood glucose-increasing glucagon administration during cardiac arrest improved survival rate, cardiac function, and neurological outcome $[52,53]$. Hyperglycaemia was associated with reduced myocardial infarction size and improved systolic function during myocardial ischaemia [37]. In traumatised patients and patients with sepsis, glucose uptake in macrophage-rich tissues is significantly increased [54]. A substantial hyperglycaemia level may overcome local or general 
microcirculation disturbances (injuries, sepsis, ischaemia) by increasing the concentration gradient, which facilitates non-insulin-dependent glucose uptake. These positive findings are accompanied by a long list of publications with negative results regarding hyperglycaemia and outcome in several diseases and critical conditions [2, 55-60]. Russo et al. retrospectively investigated clinical outcome in relation to mean blood glucose during the first $96 \mathrm{~h}$ after hospital admission in comatose survivors of out-of-hospital cardiac arrest with an initial shockable rhythm. They found that higher mean blood glucose levels during the first $96 \mathrm{~h}$ after admission were associated with increased rates of death and severe neurological dysfunction [61]. However, initial blood glucose level could be a surrogate marker of ischaemic insult severity during cardiac arrest [62].

After all, measuring blood glucose during pre-hospital care of trauma patients is easy, rapid, inexpensive and may yield additional information to estimate or complement clinical assessment of a patient's pre-hospital situation as a whole.

\section{Limitations}

Limitations of this study are its retrospective design, although all data were collected prospectively.

In our study about $46 \%$ of the trauma patients were excluded mostly due to missing prehospital glucose measurement or ECG rhythm documentation (Fig. 1). Thus, we cannot exclude selection bias, especially in the more severe cases in which HEMS physicians focus on supporting vital functions rather than on lab investigations. Patients in category NACA 7 were more numerous in the excluded population than in study patients.

In addition, we have no in-hospital data. In particular, we lack information on the frequencies of confirmed diagnoses and injury patterns, the in-hospital course of blood glucose concentrations and the ultimate outcome. However, this does not affect the core parameters of our study, initial ECG and on-site blood glucose concentrations. Worse, there is no on-site information available about pre-existing diseases such as diabetes, which probably influenced the course. The prevalence of diabetes in the German population is quoted as being 7-8\% [44]. Accordingly, about 1500 patients in the study population may have been diagnosed with diabetes. We do not know the frequency of study patients with diabetes complicated by vascular and end-organ damage and we cannot tell how many of them were under anticoagulation therapy or had taken anti-diabetic drugs. Furthermore, our results regarding outcome of hypoglycaemic trauma patients do not consider administration of glucose in half of them. The extent to which oral anti-diabetic drugs or insulin may influence blood glucose concentrations during trauma and shock is not known and may vary individually with the time of drug ingestion/administration, the extent of oral carbohydrate intake, and the individual patient's stress response. In recent studies it was reported that stress-induced hyperglycaemia rather than diabetic hyperglycaemia is associated with higher mortality in trauma $[42,43]$.

Another problem may arise from differences in pointof-care devices and with either venous or capillary blood measurements when haemodynamic shock developed. Routinely, blood glucose concentrations in pre-hospital trauma patients were measured from blood drawn from venous access before any drug or volume administration. However, we cannot exclude that in selected cases capillary blood glucose was measured by ear or finger sticks. The literature shows contradictory conclusions regarding the impact of venous vs. capillary blood glucose measurements, the existence of shock or the administration of catecholamines. In addition, the limited precision of point-of-care devices is well-known, especially when blood glucose concentrations are extremely high or low [63-65]. In this study, measurements of blood glucose concentration were conducted while establishing the initial iv access and before drug administration, for which reason the influence of external catecholamines (e.g. in the context of cardiopulmonary resuscitation) can be excluded as far as possible.

\section{Conclusions}

In adult trauma patients, higher pre-hospital blood glucose levels were related to tachycardic and shockable rhythms. Cardiac arrest was more frequently observed in hypoglycaemic and hyperglycaemic pre-hospital trauma patients. The rate of ROSC rose significantly with initial blood glucose. Blood glucose measurements in addition to common vital parameters (GCS, heart rate, blood pressure, breathing frequency) may help identify patients at risk for cardiopulmonary arrest and dysrhythmias. Therefore, it may be prudent to routinely measure blood glucose concentration during initial emergency care in pre-hospital trauma patients.

\section{Abbreviations \\ ECG: electrocardiogram; GCS: Glasgow Coma Scale; HEMS : Helicopter Emergency Medicine Service; IDI : integrated discrimination improvement; NACA : National Advisory Committee for Aeronautics; NRI : net reclassification improvement; PEA: Pulseless electrical activity; ROSC: Return of spontaneous circulation}

\section{Acknowledgments}

The authors wish to thank all emergency physicians and paramedics of the German Helicopter Emergency Medicine Service of the ADAC for their devoted work and for collecting this important and valuable data set over several years. The authors also thank Beatrice Möller for her demanding data editing work.

Funding

The study was funded by departmental resources only.

Availability of data and materials

All data that support the findings of this study are available from the corresponding author upon reasonable request. 


\section{Authors' contributions}

JK and SS conceived the study, examined data quality, analysed data and drafted the manuscript. WL analysed data and revised the manuscript substantially. $\mathrm{HU}$ and NU provided statistical advice on study design and analysed the data. MWN and DW revised the manuscript. TS collected data and controlled data quality. All authors contributed substantially to its revision. No author has a potential conflict of interest with regard to the content of this manuscript. The study was supported by departmental resources only. All authors read and approved the final manuscript.

\section{Ethics approval and consent to participate}

This retrospective study was approved by the Ethics Committee of the Medical Association of the Saarland (Ärztekammer des Saarlands, No. 69/14, 24/04/2014, Chairman Prof. Dr. med. Gerd Rettig-Stürmer) and by the Institutional Review Board.

\section{Consent for publication}

The manuscript does NOT contain any patient's personal data. All data used in this analysis were anonymised and thus the Ethical Committee withdraw the requirement for patients or next of kin to consent to take part in the trial. Therefore, the authors state: "Not applicable in this section".

\section{Competing interests}

The authors declare that they have no competing interests.

\section{Publisher's Note}

Springer Nature remains neutral with regard to jurisdictional claims in published maps and institutional affiliations.

\section{Author details}

'Department of Anaesthesia and Intensive Care Medicine, Medical University of Innsbruck, Anichstrasse 35, 6020 Innsbruck, Austria. ${ }^{2}$ Department of General and Surgical Intensive Care Medicine, Medical University of Innsbruck, Anichstrasse 35, 6020 Innsbruck, Austria. ${ }^{3}$ Department of Statistics, Faculty of Economics and Statistics, University of Innsbruck, Universitätsstrasse 15, 6020 Innsbruck, Austria. ${ }^{4}$ Department of Medical Statistics, Informatics and Health Economics, Medical University of Innsbruck, Schöpfstrasse 41/1, 6020 Innsbruck, Austria. ${ }^{5}$ University of Groningen, University Medical Centre Groningen, Hanzeplein 1, 9713 Groningen, GZ, Netherlands. ${ }^{6} \mathrm{German}$ Helicopter Emergency Medical Services (ADAC Luftrettung gGmbH), Hansastrasse 19, 80686 Munich, Germany. ${ }^{7}$ Emergency Medical Services of the Saarland, Saarpfalz-Park 9, 66450 Bexbach, Germany. ${ }^{8}$ Formerly: Quality Management of the German Helicopter Emergency Medical Services (ADAC Luftrettung gGmbH), Hansastrasse 19, 80686 Munich, Germany. ${ }^{9}$ Department of Anaesthesia and Intensive Care Medicine, Medical University of Innsbruck, Anichstrasse 35, 6020 Innsbruck, Austria.

\section{Received: 27 February 2018 Accepted: 11 June 2018}

\section{Published online: 13 July 2018}

\section{References}

1. Bilotta F, Caramia R, Paoloni FP, Delfini R, Rosa G. Safety and efficacy of intensive insulin therapy in critical neurosurgical patients. Anesthesiology. 2009;110:611-9.

2. Capes SE, Hunt D, Malmberg K, Pathak P, Gerstein HC. Stress hyperglycaemia and increased risk of death after myocardial infarction in patients with and without diabetes: a systematic overview. Lancet. 2000;355:773-8.

3. Van den Berghe G, Wilmer A, Hermans G, Meersseman W, Wouters PJ, Milants I, et al. Intensive insulin therapy in the medical ICU. N Engl J Med. 2006;354:449-61.

4. Kreutziger J, Wenzel V, Kurz A, Constantinescu MA. Admission blood glucose is an independent predictive factor for hospital mortality in polytraumatized patients. Intensive Care Med. 2009;35:1234-9.

5. Kreutziger J, Schlaepfer J, Wenzel V, Constantinescu MA. The role of admission blood glucose in outcome prediction of surviving patients with multiple injuries. J Trauma. 2009;67:704-8.

6. Vogelzang M, Nijboer JM, van der Horst IC, Zijlstra F, ten Duis HJ, Nijsten MW. Hyperglycaemia has a stronger relation with outcome in trauma patients than in other critically ill patients. J Trauma. 2006;60:873-7.

7. Konesky KL, Guo WA. Revisiting traumatic cardiac arrest: should CPR be initiated? Eur J trauma Emerg Surg. 2017; in press
8. Messelken M, Schlechtriemen TH. Der minimale Notarztdatensatz MIND2. Notf Rettungsmed. 2003;6:189-92.

9. Teasdale G, Maas A, Lecky F, Manley G, Stocchetti N, Murray G. The Glasgow coma scale at 40 years: standing the test of time. Lancet Neurol. 2014;13: 844-54.

10. Tryba M, Brüggemann $\mathrm{H}$, Echtermeyer V. Classification of diseases and injuries in emergency medical services [Klassifizierung von Erkrankungen und Verletzungen in Notarztrettungssystemen]. Notfallmedizin. 1980;6: 725-7.

11. Bilhimer MH, Treu CN, Acquisto NM. Current practice of hypoglycaemia management in the ED. Am J Emerg Med. 2017;35:87-91.

12. Bagshaw SM, Bellomo R, Jacka MJ, Egi M, Hart GK, George C. The impact of early hypoglycaemia and blood glucose variability on outcome in critical illness. Crit Care. 2009;13:R91.

13. van lersel FM, Slooter AJ, Vroegop R, Wolters AE, Tiemessen CA, Rosken RH, et al. Risk factors for hypoglycaemia in neurocritical care patients. Intensive Care Med. 2012;38:1999-2006.

14. ADAC Stiftung. Wie kann ich Arzt auf einem Rettungshubschrauber werden. 2018. https://stiftung.adac.de/luftrettung/fragen-antworten. aspx?Componentld=294107\&SourcePageld=291799. Accessed 15 Mai 2018.

15. Soar J, Nolan JP, Böttiger BW, Perkins GD, Lott C, Carli P, et al. European resuscitation council guidelines for resuscitation 2015: Section 3. Adult advanced life support. Resuscitation. 2015;95:100-47.

16. Hastie TJ, Tibshirani RJ. Generalized additive models. 1st ed. London: Chapman \& Hall/CRC Press; 1990

17. Eilers PHC, Marx BD. Flexible smoothing using B-splines and penalized likelihood. Stat Sci. 1996;11:89-121.

18. R Development Core Team. R. A language and environment for statistical computing. In: The R Foundation for Statistical Computing; 2011. http:// www.R-project.org/. Accessed 15 December 2016.

19. Wood SN. GAMs with GCV/AIC/REML smoothness estimation and GAMMs by PQL. In: R package version 1.8.16; 2016. https://CRAN.R-project.org/ package $=$ mgcv. Accessed 15 December 2016.

20. Brunauer A, Kokofer A, Bataar O, Gradwohl-Matis I, Dankl D, Dunser MW. The arterial blood pressure associated with terminal cardiovascular collapse in critically ill patients: a retrospective cohort study. Crit Care. 2014;18:719.

21. Goodwin GW, Taylor CS, Taegtmeyer H. Regulation of energy metabolism of the heart during acute increase in heart work. J Biol Chem. 1998;273: 29530-9.

22. Kreutziger J, Rafetseder A, Mathis S, et al. Admission blood glucose predicts hemorrhagic shock rather than in-hospital mortality in multiple injury patients. Injury. 2015;46:15-20.

23. Kreutziger J, Lederer W, Schmid S, Ulmer H, Wenzel V, Nijsten MW, et al. Blood glucose concentrations in prehospital trauma patients with traumatic shock: a retrospective analysis. Eur J Anaesthesiol. 2018;35:33-42.

24. Marik PE, Bellomo R. Stress hyperglycemia: an essential survival response! Crit Care. 2013;17:305

25. Ensinger H, Stein B, Jager O, Grunert A, Ahnefeld FW. Relationship between infusion rates, plasma concentrations, and cardiovascular and metabolic effects during the infusion of norepinephrine in healthy volunteers. Crit Care Med. 1992;20:1250-6.

26. Hart BB, Stanford GG, Ziegler MG, Lake CR, Chernow B. Catecholamines: study of interspecies variation. Crit Care Med. 1989;17:1203-22.

27. Molina PE, Malek S, Lang CH, Qian L, Naukam R, Abumrad NN. Early organspecific hemorrhage-induced increases in tissue cytokine content: associated neurohormonal and opioid alterations. Neuroimmunomodulation. 1997:4:28-36.

28. Shimizu T, Yu HP, Hsieh YC, Choudhry MA, Suzuki T, Bland Kl, Chaudry IH. Flutamide attenuates pro-inflammatory cytokine production and hepatic injury following trauma-hemorrhage via estrogen receptor-related pathway. Ann Surg. 2007;245:297-304.

29. Blumberg D, Hochwald S, Burt M, Donner D, Brennan MF. Tumor necrosis factor alpha stimulates gluconeogenesis from alanine in vivo. J Surg Oncol. 1995:59:220-4.

30. Meyer C, Stumvoll M, Welle S, Woerle HJ, Haymond M, Gerich J. Relative importance of liver, kidney, and substrates in epinephrine-induced increased gluconeogenesis in humans. Am J Physiol Endocrinol Metab. 2003;285:E819-26.

31. Stumvoll M, Chintalapudi U, Perriello G, Welle S, Gutierrez O, Gerich J. Uptake and release of glucose by the human kidney. Postabsorptive rates and responses to epinephrine. J Clin Invest. 1995;96:2528-33. 
32. Dungan KM, Braithwaite SS, Preiser JC. Stress hyperglycaemia. Lancet. 2009; 373:1798-807.

33. Lang CH, Dobrescu C. Gram-negative infection increases noninsulinmediated glucose disposal. Endocrinology. 1991;128:645-53.

34. Hamlin GP, Cernak I, Wixey JA, Vink R. Increased expression of neuronal glucose transporter 3 but not glial glucose transporter 1 following severe diffuse traumatic brain injury in rats. J Neurotrauma. 2001;18:1011-8.

35. Losser MR, Damoisel C, Payen D. Bench-to-bedside review: glucose and stress conditions in the intensive care unit. Crit Care. 2010;14:231.

36. Ma G, Al-Shabrawey M, Johnson JA, Datar R, Tawfik HE, Guo D, Caldwell RB, Caldwell RW. Protection against myocardial ischemia/reperfusion injury by short-term diabetes: enhancement of VEGF formation, capillary density, and activation of cell survival signaling. Naunyn Schmiedeberg's Arch Pharmacol. 2006;373:415-27.

37. Malfitano C, Alba Loureiro TC, Rodrigues B, Sirvente R, Salemi VM, Rabechi $\mathrm{NB}$, et al. Hyperglycaemia protects the heart after myocardial infarction: aspects of programmed cell survival and cell death. Eur J Heart Fail. 2010;12: 659-67.

38. Friedman SG, Pearce FJ, Drucker WR. The role of blood glucose in defense of plasma volume during hemorrhage. J Trauma. 1982;22(2):86-91.

39. Pearce FJ, Drucker WR. Glucose infusion arrests the decompensatory phase of hemorrhagic shock. J Trauma. 1987;27:1213-20.

40. McCowen KC, Malhotra A, Bistrian BR. Stress-induced hyperglycemia. Crit Care Clin. 2001;17:107-24.

41. Thorell A, Nygren J, Ljungqvist O. Insulin resistance: a marker of surgical stress. Curr Opin Clin Nutr Metab Care. 1999;2:69-78.

42. Kerby JD, Griffin RL, MacLennan P, Rue LW 3rd. Stress-induced hyperglycemia, not diabetic hyperglycemia, is associated with higher mortality in trauma. Ann Surg 2012;256:446-452.

43. Bosarge PL, Shoultz TH, Griffin RL, Kerby JD. Stress-induced hyperglycemia is associated with higher mortality in severe traumatic brain injury. J Trauma Acute Care Surg. 2015;79:289-94.

44. Deutsche Diabetes Hilfe. Deutscher Gesundheitsbericht Diabetes 2017: Deutsche Diabetes Hilfe; 2017. https://www.diabetesde.org/system/files/ documents/gesundheitsbericht_2017.pdf. Accessed 26 Dec 2017.

45. Alfonsi P, Nourredine KE, Adam F, Chauvin M, Sessler DI. Effect of postoperative skin-surface warming on oxygen consumption and the shivering threshold. Anaesthesia. 2003;58:1228-34.

46. Wouters MPR, van der Weerd L, van Putten TS, Wendt KW, Nijsten MW. Incidence, causes and consequences of early hypoglycaemia in severe trauma patients. Paris: Abstract presented at the ESICM; 2013.

47. Chen JH, Michiue T, Inamori-Kawamoto O, Ikeda S, Ishikawa T, Maeda H. Comprehensive investigation of postmortem glucose levels in blood and body fluids with regard to the cause of death in forensic autopsy cases. Leg Med (Tokyo). 2015;17:475-82.

48. Strapazzon G, Nardin M, Zanon P, Kaufmann M, Kritzinger M, Brugger $H$. Respiratory failure and spontaneous hypoglycemia during noninvasive rewarming from 24.7 degrees $C$ ( 76.5 degrees F) core body temperature after prolonged avalanche burial. Ann Emerg Med. 2012;60:193-6.

49. Nehme Z, Nair R, Andrew E, Bernard S, Lijovic M, Villani M, et al. Effect of diabetes and pre-hospital blood glucose level on survival and recovery after out-of-hospital cardiac arrest. Crit Care Resusc. 2016;18:69-77.

50. Mentzelopoulos SD, Malachias S, Chamos C, Konstantopoulos D, Ntaidou T, Papastylianou A, et al. Vasopressin, steroids, and epinephrine and neurologically favorable survival after in-hospital cardiac arrest: a randomized clinical trial. JAMA. 2013;310:270-9.

51. Lennmyr F, Molnar M, Basu S, Wiklund L. Cerebral effects of hyperglycaemia in experimental cardiac arrest. Crit Care Med. 2010;38:1726-32.

52. Raffay V, Chalkias A, Lelovas P, Karlis G, Koutsovasilis A, Papalois A, et al. Addition of glucagon to adrenaline improves hemodynamics in a porcine model of prolonged ventricular fibrillation. Am J Emerg Med. 2014;32:139-43.

53. Dokken BB, Piermarini CV, Teachey MK, Gura MT, Dameff CJ, Heller BD, et al. Glucagon-like peptide-1 preserves coronary microvascular endothelial function after cardiac arrest and resuscitation: potential antioxidant effects. Am J Physiol Heart Circ Physiol. 2013;304:H538-46.

54. Lang CH, Dobrescu C, Meszaros K. Insulin-mediated glucose uptake by individual tissues during sepsis. Metabolism. 1990;39:1096-107.

55. Meynaar IA, Eslami S, Abu-Hanna A, van der Voort P, de Lange DW, de Keizer N. Blood glucose amplitude variability as predictor for mortality in surgical and medical intensive care unit patients: a multicenter cohort study. J Crit Care. 2012;27:119-24.
56. Fiordaliso F, Leri A, Cesselli D, Limana F, Safai B, Nadal-Ginard B, et al. Hyperglycaemia ac-tivates p53 and p53-regulated genes leading to myocyte cell death. Diabetes. 2001;50:2363-75.

57. Berrou J, Fougeray S, Venot M, Chardiny V, Gautier JF, Dulphy N, et al. Natural killer cell function, an important target for infection and tumor protection, is impaired in type 2 diabetes. PLoS One. 2013;8:e62418.

58. Undas A, Wiek I, Stepien E, Zmudka K, Tracz W. Hyperglycaemia is associated with enhanced thrombin formation, platelet activation, and fibrin clot resistance to lysis in patients with acute coronary syndrome. Diabetes Care. 2008;31:1590-5.

59. Wang JY, Yang JH, Xu J, Jia JY, Zhang XR, Yue XD, et al. Renal tubular damage may contribute more to acute hyperglycaemia induced kidney injury in non-diabetic conscious rats. J Diabetes Complicat. 2015;29:621-8.

60. Rosso C, Pires C, Corvol JC, Baronnet F, Crozier S, Leger A, et al. Hyperglycaemia, insulin therapy and critical penumbral regions for prognosis in acute stroke: further insights from the INSULINFARCT trial. PLoS One. 2015;10:e0120230.

61. Russo JJ, James TE, Hibbert B, Ramirez FD, Simard T, Osborne C, et al. CAPITAL Investigators. Hyperglycaemia in comatose survivors of out-ofhospital cardiac arrest. Eur Heart J Acute Cardiovasc Care. 2016; in press

62. Kim SH, Choi SP, Park KN, Lee SJ, Lee KW, Jeong TO, et al. Korean hypothermia network investigators. Association of blood glucose at admission with outcomes in patients treated with therapeutic hypothermia after cardiac arrest. Am J Emerg Med. 2014;32:900-4.

63. Ramachandran B, Sethuraman R, Ravikumar KG, Kissoon N. Comparison of bedside and laboratory blood glucose estimations in critically ill children with shock. Pediatr Crit Care Med. 2011;12:e297-301.

64. Pulzi Júnior SA, Assunção MS, Mazza BF, Fernandes Hda S, Jackiu M, Freitas FG, Machado FR. Accuracy of different methods for blood glucose measurement in critically ill patients. Sao Paulo Med J. 2009;127:259-65.

65. Aslan B, Stemp J, Yip P, Gun-Munro J. Method precision and frequent causes of errors observed in point-of-care glucose testing:a proficiency testing program perspective. Am J Clin Pathol. 2014;142:857-63.

\section{Ready to submit your research? Choose BMC and benefit from:}

- fast, convenient online submission

- thorough peer review by experienced researchers in your field

- rapid publication on acceptance

- support for research data, including large and complex data types

- gold Open Access which fosters wider collaboration and increased citations

- maximum visibility for your research: over $100 \mathrm{M}$ website views per year

At BMC, research is always in progress.

Learn more biomedcentral.com/submissions 